Behavioural Sciences | 'Apo' Aporosa

\title{
De-mythologizing and re-branding the traditional drink kava
}

What do you call journalism, or more importantly research, that is supported by repetitive misinformation, resulting in an accepted but incorrect, the kava phant, named Piper methysticum or 'intoxicating pepper' by a naturalist who accompanied Captain James Cook on his voyage to the Pacific some 250 years ago. That name, which inferred that kava causes intoxication when consumed, is one of several "myths" that have the years, and Dr' 'Apo' Aporosa from New Zeal's 'Anivoros from New Zealand's University re-evaluate this icon of Pacific identity and correct these misunderstandings. ava, a plant lacking seeds or a means to self-propagate, is
believed to have first originated believed to have first origina
orthern Vanuatu thousands of years ago. Those origins add to kava's as a 'plant of the gods'. For instance, 'who else other than the Pacific ancestral gods would have planted and tended kava until the arrival of the first indigenous explorers into the Pacific around 2500 years ago?'; a people who then spread kava throughout the region along migration trade routes. Used in traditional medicine, its roots are als ground and steeped in water to mak a drink which continues to be used by Pacific peoples today to infuse spiritual power into ceremony and significant life events, and to facilitate discussion and socialisation.

Kava was given its botanical name Per methysticum, literally meaning Forster, a naturalist who voyaged to the Pacific with Captain James Cook in the 1770s. However experts now believe that Forster was misguided in that

naming, which inferred kava was an alcohol and caused intoxication: this is one of several myths that kava's 'discovery' by the West Today, kava use has spread around the world and is now also used by nonPacific peoples as an alcoh sttings, and as a nicrathoth supplement. After various scar supplement. After various scares that usage could result in death, kava was banned in several countries starting the early 2000s. However, following Organization (WHO) has advised kava use has an acceptable level of risk when mixed with water and consumed as a beverage.

Dr 'Apo' Aporosa, a Research Fellow at the University of Waikato in New Zealand, has more than 20 years' experience as a development practitioner in New Zealand and Fiji, from where his mother's family originates. An acknowledged expert on kava, he believes the time is right to demythologise and re-brand what is for him, and for other Pacific slanders, their leading icon of identity he presents his review of the legal, historical and pharmacological research Science

\section{PRODUCTION AND}

(c)

Aporosa describes kava as a "slightly produces subtle relaxant soporific without marked euphoria or intoxication"

In traditional medicine, kava is used for its antifungal and antibacterial properties, mild anaesthetic and analgesic effects, and to relieve stress and anxiety. In pharmacological terms the relaxant effect is caused by psychoactive compounds called kavalactones which act on recepto in the brain and central nervous system. The anti-anxiety benefits
have led to kava being prescribed by Western healthcare professionals s an alternative to benzodiazepine showing positive effects in severl cancer studies.

Aporosa distinguishes between two means of kava use: the traditional way, in which water is used to make a drink from the roots of the plant; and the practice of some modern commercial herbal remedy producers, in which the kavalactones are extracted from the plant and manufactured into table and syrup form.

Leading kava-producing nations working with the United Nations and WHO

re expected to detail quality control standards for kava in 2020. Kava's many positive attributes and safety reports the have "myths", some of which have oren been published in reputable peer reviewed ournals and books.

\section{ALCOHOL AND}

\section{ADDICTION "MYTHS"}

e that it causes and is addictive. Researchers argue that these ideas first developed from Forster's naming of kava Piper methysticum

together with misunderstandings by

early colonial observers. Kava contains no alcohol or hallucinogenic properties, and Aporosa says that the scientific evidence also shows that, though it oes net dinhibit the a corol, toxication lead to violent behaviour or makedly affect the drinkers' cognitive abilities and functioning. These are easons why kava is popular in sociocultural settings where it is used to stimulate "clear-headed discussion".

Aporosa believes that the idea that kava is addictive developed from the observations of $19^{\text {th }}$ century colonialists. He quotes one report, for example that said drinkers were "tormented with cravings" for kava, as with "passions cha similar nature such as morphinism and alcoholism". However, Aporosa points out that the writer of that report was quoting others, and that the cova wasto cated of did "ot believe

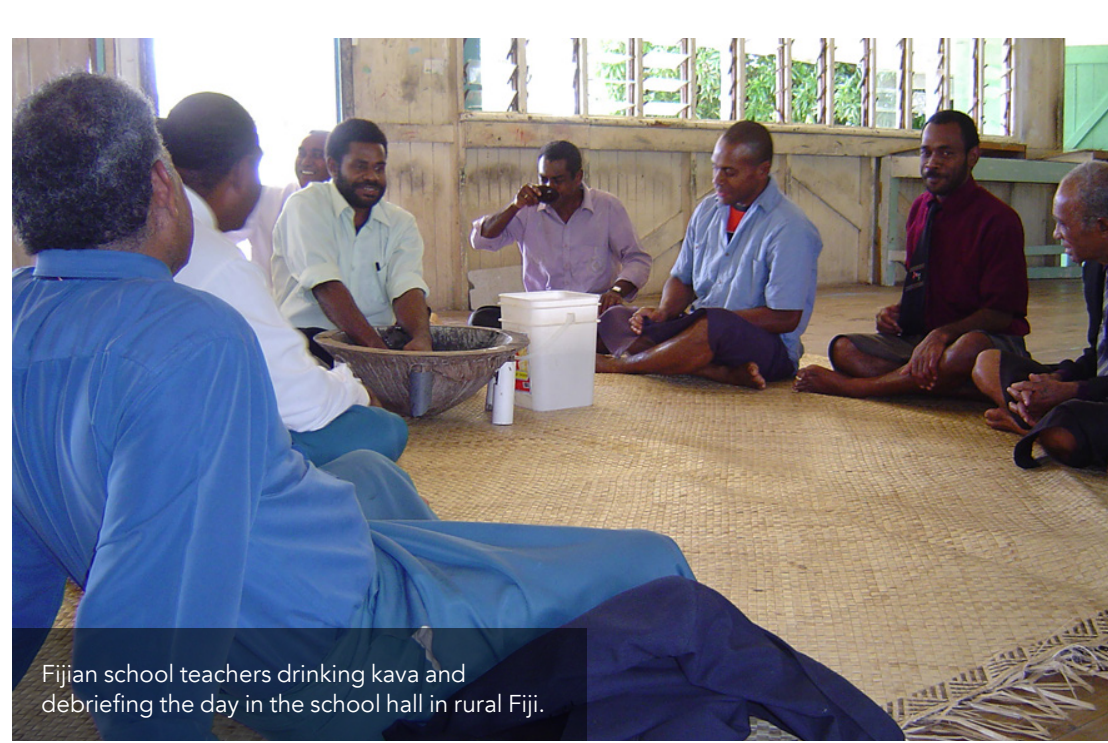

We don"t drink kava for the taste; it's about culture, practice and connection, something most non-Pacific Islanders can't understand.

Aporosa says that while there have that aids relaxation and allows users been recent suggestions that regular use can lead to chemical withdrawal syndrome, most experts disagree. Moreover, he cites the use of kava in several drug addiction therapy programmes to mitigate alcoho tobacco and cocaine craving, and to reduce withdrawal symptoms in benzodiazepine addiction. Kava's non-addictive subtle effects have also encouraged its use beyond Pacific spaces, including the United States where franchised kava bars seeking to consume a beverage

\section{LIVER DAMAGE "MYTH"} 's's the supposed effect of kava on the liver that has received the most negative media coverage. Aporosa explains that this suggestion emerged in Western Europe in early 2000 following reports that 83 patients taking kava tablets as a herbal remedy had Federal Administrative Court ruled in 2014 that it was unlikely that kava

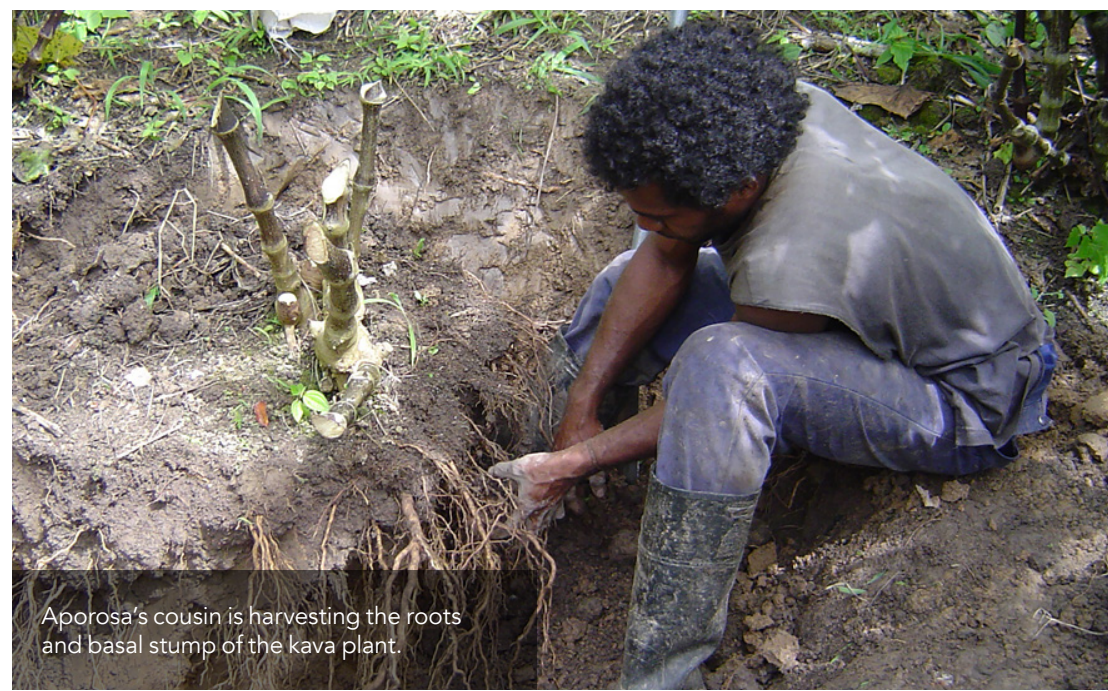


had caused the deaths, that liver tarnished kava as dangerous.

Showman and colleagues summarise: "Only a fraction of a handful of cases reviewed for liver toxicity could be the co-ingestion of other medications/ supplements." Additionally, the WHO second kava risk assessment in 2016 eported: "On balance, the weight of evidence from both a long history of use of kava beverage and from the more recent research finding beverage to be consumed with an alth risk."

Aporosa notes that this level of risk gives kava a vastly higher degree and tobacco, or to overthe-colnter medications like paracetamol.

\section{OTHER "MYTHS"}

ice on kava's safety level, many journalists and some research kava's supposed negative effects. Aporosa says that these "myths"

are often accompanied by uninformed opinion such as kava "looks awful and beverage looks similar to miky coffee whereestribed as looking "awful") whereas taste can vany according to . tastes like unsweetened chocol te.

But we don't drink kava for the taste; its about culture, practice and connection, something most non-Pacific Islanders

can't understand.

Aporosa does accept that high kava use over a prolonged period can cause kava dermopathy, or a drying and peeling of the skin. However, this subsides a we or so after use is slowed or ceased, without any residual effects. Regardless, this has not stopped the "myth" that kava dermopathy "proves" kava is langerous, nor has it limited criticism this hermes dnelge from kava was so rare as to be consumption and most of those involved indicate that it is possible for kava tastes worse". He explains that kava (although he has never heard milky linking kava demopathy wh abusive

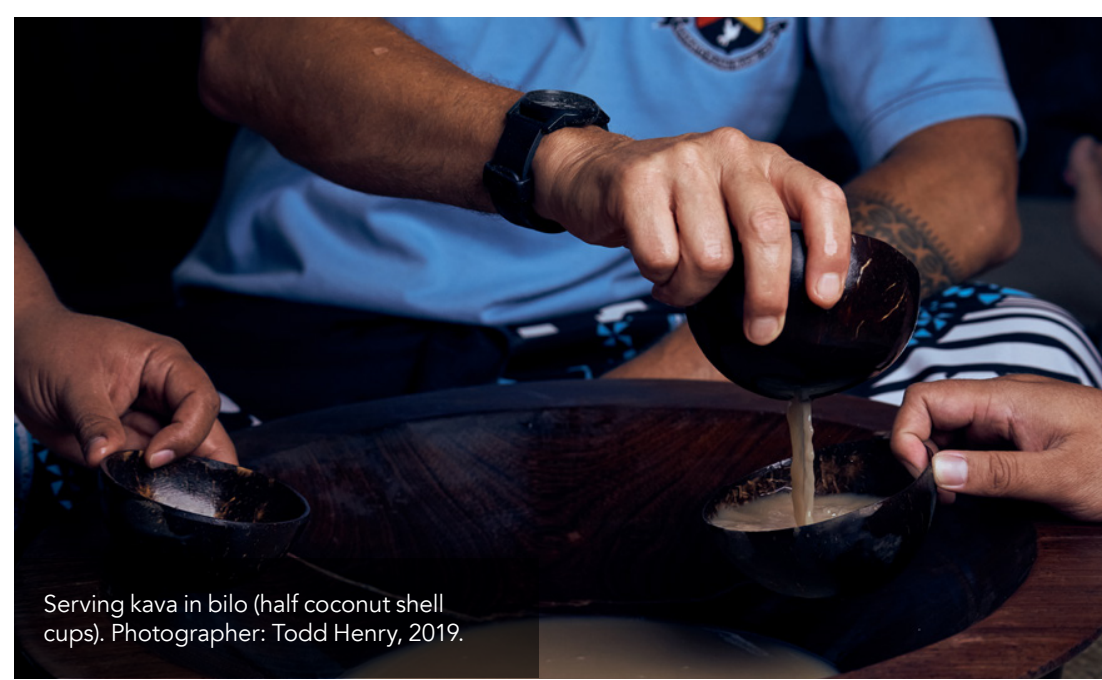

not look attractive to some, to others it sensational stories are more exciting is considered to represent the kava user's enthusiastic engagement with their Aporos a dis that peoplo and attract more readers and viewers. But ing (B) these with "primitiveness" in contrast problems such as the reddening of facial to "modern, civilised behaviour". skin and a bulbous nose. However, these He link his tole" - traditional kova concerns are rarely spoken of, regardless and acceptable - traditional kava use
that these symptoms represent medical and the serving of the beverage from As for the claim that kava drinking is a shared kava bowl in a half coconut a bottle displaying a professional label

\section{It is time to stop maligning kava through} modernity-framed prejudice and discrimination and rebrand kava.

from their families", Aporosa argues that served in a glass - and the tendency of excessive television watching, gaming or some people to place a higher value on thing - it's about how people choose in len sytories over tradition prepared to spend their time "Kava, as opposed to personal choice, or even poor choice, has become the scape-goat and the point of criticism", says Aporosa.

\section{REASONS AND CONCLUSIONS} So why have these "myths" about kava also in academic research? As Aporos says: "Why the lies, discredit and targeted malignment of our Pacific icon of identity?"

Aporosa believes there are two main reasons. The first is that the negative poor research which recycles old stories and misin to the "facts", or baying originating from a rural, isolated village.

Aporosa believes it is time to stop maligning kava through "modernityframed prejudice and discrimination" medicinal substance and socio-cultural acilitator that is no longer seen as ailler but rather as a cure. He says: "When examining the history of kav used in traditional contexts, and considering the evidence now available, it is possible to de-mythologise kava, not only on the grounds that it is a elaxant, but also on its life-enhancing medicinal properties and as an thernative to alcohol-understanding makers, aporosa adds that people who use that hern, unlike kava dermopathy. myths are a result of lazy journalism and

\section{Behind the Research \\ Dr 'Apo' Aporosa}

E: apo.aporosa@waikato.ac.nz W: $\mathbf{h t t p s : / / w w w . a p o r o s a . n e t ~ W : ~} \mathbf{h t t p s : / / w w w . w a i k a t o . a c . n z / s t a f f - p r o f i l e s / p e o p l e / a a p o r o s a ~}$

\section{Research Objectives}

Dr Aporosa explores and debunks the myths surrounding the traditional drink kav.

\section{Detail}

Apo Aporosa

Te Huataki Waiora School of Health

University of Waikato

Private Bag 3105
Hamilton 3240

New Zealand

Bio

Dr 'Apo' Aporosa is maternally related to the village of Naduri in Macuata, Fiji. He has a doctorate in Development Studies from Massey University (New Zealand). Apo is the 2019 New Zealand Health Research Council Sir Thomas Davis Te Patu Kite Rangi Arik (Research) Fellow. Based at Te Huataki Waiora School of Health at The University of Waikato and also working with the School of Psychology's Traffic and Road Safety Research Group, Apo teaches, supports the Pacific student cohort, and is investigating driver safety following kava use at traditional consumption volumes.

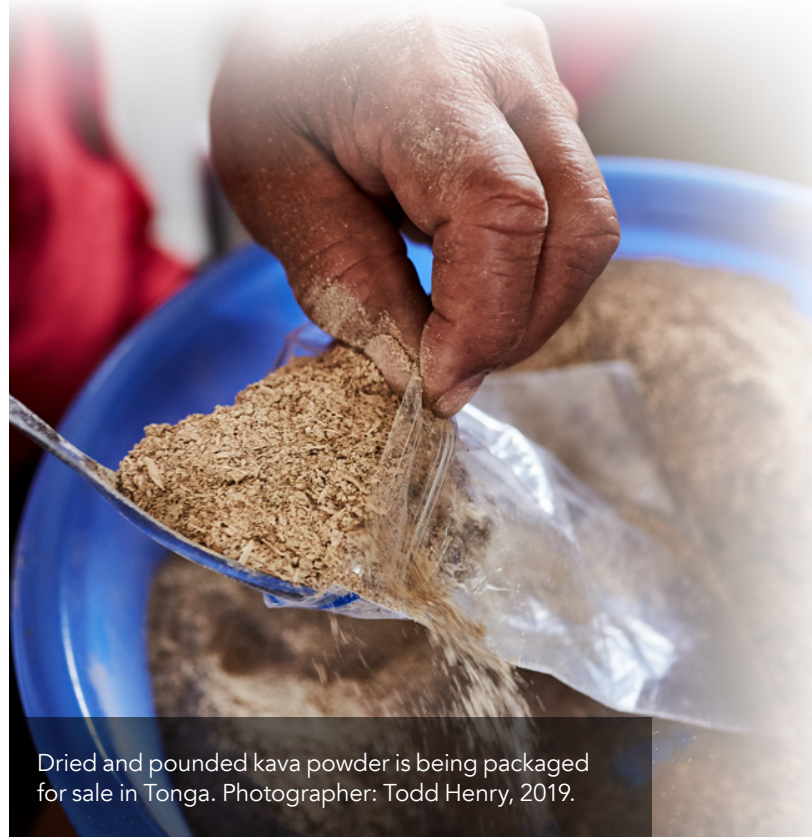

\section{References}

Abbott, P. (2016). Kava: A review of the safety of traditional and recreational beverage consumption (Technical Report) Food and Agriculture Organization of the United Nations

Aporosa, S. A., Atkins, M., \& Brunton, R. (2020). Kava drinking in tradkional settings: Towards understanding Psychopharmacology: Clinical and Experimental, e2725 (early view), 1-11. Available at: doi:10.1002/hup.2725 Aporosa, A. (2019). De-mythologizing and re-branding Policy and Law 5, 1-13.

Aporosa, A. (2019). Kava and ethno-cultural identity in Oceania. In S. Ratuva (Ed.), The Palgrave handbook Nature.

Showman, A. F., Baker, J. D., Linares, C., Naeole, C. Contis, R., Johnston, E., Turner, H. et al. (2015). (Piper methysticum) toxicology. Fitoterapia 100, 56-67.

\section{Personal Response}

Your comments suggest that kava is traditionally drunk only by men. Do women also drink kava

II Unlike Fiji, kava use in Vanuatu, Tonga and Samoa limited to mixing and serving kava (in Tonga and Samoa) and rarely consuming the beverage unless for medicinal purposes. This is changing though, with mixed gender popular, something we have been doing in areas of Fili for many generations. In diasporic Pacific environments and kava bar settings such as in the United States, mixed-gender kava use is commonplace.
WAIKATO 